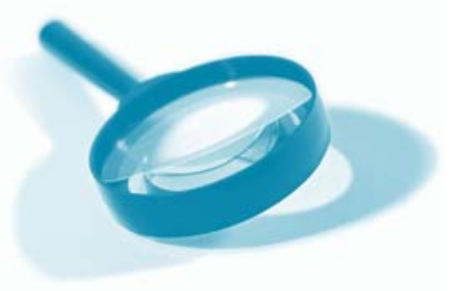

Simon B Bedford* and

\section{Transitions mark a life as times of change, where an individual may have tenuous control over events or circumstances, may be able to rise to the challenge of the new and grow, or may be unable to successfully move in the chosen direction.}

\section{Glennys O'Brien \\ School of Chemistry \\ University of Wollongong \\ Wollongong NSW 2522 \\ Australia \\ *simon_bedford@uow.edu.au}

L

\title{
A view of first year tra nsition from Down Under
}

\begin{abstract}
Transition from school to university life is a complex process and cannot be accomplished in a single event. There is now a move away from concentrating activities just into 'freshers' week or week zero to what are termed more longitudinal induction programmes. Only key orientation and social engagement events are provided in week zero and the more valuable aims of a successful first year experience (FYE) are achieved by curriculum based support and spreading activities throughout the year. With the growing challenges facing such UK induction programmes from increasing student numbers, greater diversity and fewer resources we show here how one Australian system faces up to those challenges and has found possible ways forward.

\section{Introduction}

Transitions mark a life as times of change, where an individual may have tenuous control over events or circumstances, may be able to rise to the challenge of the new and grow, or may be unable to successfully move in the chosen direction. One transition marked by great challenge in many aspects is that facing the first year student arriving at your university. As part of the Australian Federal Government policies ${ }^{1,2,3}$, greater numbers of students with diverse backgrounds and learning aims are coming into the university where there has to be provision of a learning environment and opportunity which has no impedance to students successfully entering and moving through the degree programmes to graduate, prepared for the next transition to a professional working life.
\end{abstract}

The transition is no longer viewed as a short induction phase pertaining to the week before lectures start ${ }^{4}$ which may include a quick information session followed by a barbeque on the lawn (Australia) or afternoon tea (United Kingdom) with the Head of School and academic staff. The transition encompasses the entire move from secondary education or other entry paths or the workforce through an induction/introduction programme and into the first semester, where generic support and information continue. The transition has as much to do with changes in a person's social life and living arrangements as it has to do with leaving the former educational setting of small classes and managed learning to enter tertiary study with great emphasis on the student operating independently. Thus the institution maintains interest in the welfare and progress of the student to ensure successful outcomes. The transition and the first year experience together encompass the area of research and programme development which institutions pursue to support student retention and success in the first year. This discussion reflects the developing transition programme offered at The University of Wollongong (UOW) and in the particular situation for chemistry first year with students spread across more than one faculty. 


\section{Transition background}

The transition into university and successful completion of the first year is, for many students, not a foregone conclusion; concern about retention rates ${ }^{5}$ is testimony to this issue However, much research in Australia ${ }^{4,6}$, and elsewhere ${ }^{7,8}$ has led to an understanding of some particular distinctive characteristics of the learning institution and environment that can facilitate student success and reduce difficulties. Kift ${ }^{4,9}$ has identified that first year assistance can best be delivered using a 'transition pedagogy' based on the curriculum as an organising framework, as exemplified in the FYE transition programme at Queensland University of Technology (QUT) ${ }^{4}$. Curricula which particularly support the $F Y E^{9,10}$ engage students in learning, offer timely interventions, foster belonging and are sustainably built between the teaching academics and the institution education or learning support staff. Successful transition programmes are those embedded into the programme of study and thus made relevant to the end user. While this is relatively easily implemented within

\section{Succ essful tra nsition}

\section{programmes are those embedded into the} programme of study and thus made relevant to the end user.

degree programmes delivered within a department or school, it becomes more problematic when induction/transition covers a whole science faculty containing multiple disciplines and programmes which is the norm at UOW. Furthermore, where students are enrolled on degree programmes with units of study from more than one faculty, transition support needs to be developed based on institution wide or at least cross faculty understandings, in order that the support, materials, information and advice offered via unit curricula are coherent and consistent. There is a need for academic and professional partnerships across the institution to ensure this coherency.

At the University of Wollongong individual or small teams of staff were carrying out various support introduction / induction / welcome programmes of their own for particular groups of students, which was typical of many institutions ${ }^{9,10,11}$. Following a survey of transition support in a benchmarking exercise with the University of Tasmania ${ }^{11}$ a FYE working party was set up in 2010 to establish a community of practice among first year coordinators, teachers and units supporting FYE, beginning with a series of forums of invited FYE experts ${ }^{12}$ and ultimately aimed at a holistic policy framework for first year student support. This led to the formation of the UStart programme, planned to be University wide run by students for students. The programme is not yet offered across the entire university. In 2012 the faculties of
Arts, Education, Law and Science took part, offering the programme initially to identified students and is an addition to the main enrolment day activities which register students onto their chosen programmes of study.

\section{Supporting transition in the Faculty of Science, UOW} Second year faculty of science students were used as facilitators to deliver the science UStart programme. They were given a half day training session by education faculty staff and supported by key staff within the faculty of science. Over a three month time span this small group of students (56 ) organised a half day programme that would help orientate all new first year science faculty students $(-230)$ and give them the best start to their study. As well they created an online presence in the form of a Facebook site and a web resource with key information (ustartscience.com) and organised and trained a number of student EDF (Enrolment Day Facilitators) to help them deliver these programmes on the day.

Similar peer-to-peer programmes have also been used successfully at the University of Bath, but were delivered at the Department of Chemistry level not faculty level. Thus, while some generic induction is carried out centrally the focus is mainly directed at a small group of chemistry programmes and students enrolled on these. Activities such as scavenger hunts around the science library, training in good laboratory practice, induction in health and safety training ${ }^{13}$, key skills, are carried out by small groups of students with second year chemistry students acting as facilitators. But all were directly related to the programme of study being undertaken and aimed to foster links between new students and their peers in other years taking the same programmes.

Transition to University and first year chemistry at UOW Students in the two 6-Credit Units CHEM101 and CHEM102 (general, physical and organic chemistry) at UOW are enrolled in one of a wide variety of degree programmes: chemistry, medicinal chemistry, nanotechnology, physics, geoscience, biology, conservation biology, environmental science, medical biotechnology, nutrition \& dietetics, exercise science, medical $\&$ health science, science education. The number of students enrolling in this enabling science is approximately $550-600$, of these only a small portion actually complete degrees based in the School of Chemistry: BSc(Chem), BMedChem, BNano. In addition, a number of these degree programmes are based in the Faculty of Health and Behavioural Science. Thus a substantial number of the CHEM101/102 students are taking units based in a faculty other than their 'own'.

The students' experience of transition involves several steps where information and advice may be given in a variety of ways. This is partly dependent on their background or secondary education and their degree programme. The timeline of transition leading up to day 1 is detailed below. Further support continuing into the semester is described later. Figure 1 shows part of generic online support and information, clearly following the timeline which the student experiences. 


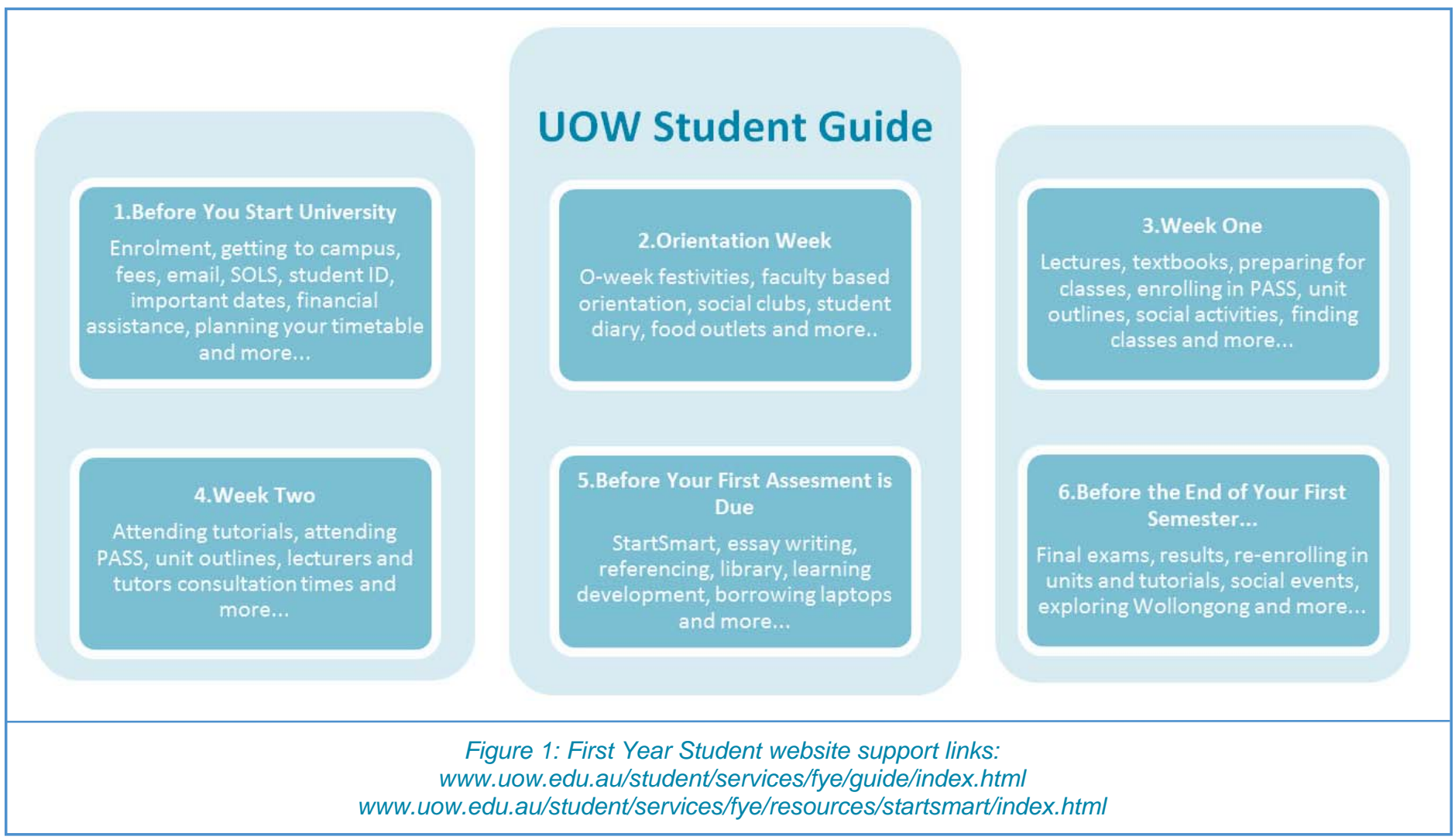

Timeline up to Day 1 of Semester:

1. Students may attend 'Options' day in early January for last minute advice from faculty staff before accepting their offered place in a particular degree programme.

2. Enrolment day: late January, final check of degree programme from academic staff and other faculty based support staff. Students in the Science faculty also take part in the UStart experience.

3. Following enrolment day, students may be attending a two week Bridging Course in Chemistry, Biology or Physics if they lack that background from senior high school studies.

4. Orientation week: (week before the start of the semester) This will include the Faculty orientation / induction covering a half day of activity meeting the Dean, the Associate Dean (Teaching and Learning), Heads of Schools and degree coordinators in the Faculty. Students enrolled in the units of study CHEM101 and CHEM102 will spend this time in the Faculty of their degree programme, not necessarily the Faculty of Science.

5. Semester begins, late February. Students begin attending the timetabled classes for each unit. Unit specific lab / workshop inductions occur within the timetabled classes.

\section{Continuing support Post Week 1:}

Unit specific support:

- $\quad$ PASS: Peer Assisted Study Sessions are provided in many first year units at UOW, including CHEM101/102. This is part of Student Support and Peer Learning, beginning in week 2.

- HELPDESK a timetabled 1 hour/day informal support. In the School of Chemistry specific unit help is offered to first year students by academic staff members in an informal setting, students do not need to make an appointment, they may simply come to the assigned room individually or in small groups. The content dealt with is determined by the students' questions. Any student enrolled in the unit may access the HELPDESK for unit support.

- Workshop classes ${ }^{14}$. First Year Chemistry classes incorporate a workshop system for problem based group learning with peer assessment; within this setting many students report favourably on developing informal support groups and networks which facilitate their overall wellbeing in their studies. 
In the UK environment, and in particular within chemistry at the University of Bath, the recruitment of students is handled via the UCAS process that can include tours of facilities and informal interviews with academic staff in the relevant department. Open days and visits to and from schools and universities further adds to the information flow. Next follows 'freshers' week that combines social engagement activities, accommodation on or near campus, and academic orientation. Due to the setting of clear A-level prerequisites for programme entry there is little need for bridging courses in chemistry although in recent times pre-university courses in mathematics have been considered ${ }^{15}$. Again the department and its staff are actively involved in the induction usually ending in a meeting of all new students with their teaching staff, most of whom will act as personal tutors through the students' university life, and delivering ongoing and relevant information at the point of need.

\section{General support:}

At UOW students in each unit have some form of early formative/summative assessment worth a small portion of the final marks in that unit before $31 \mathrm{March}$, census date (approximately Week 4). This date is important as a student may withdraw from the unit (not necessarily from their whole degree programme) by this date and incur no financial penalty for that unit in doing so. They may choose to attempt the unit again the following year. At this point their degree is not in jeopardy, but it is likely to take longer. Where students are withdrawing, they are more likely to discuss this with their degree coordinator rather than with individual unit coordinators in the first instance. They are also likely to discuss their circumstances with the Associate Dean (Teaching and Learning) in their faculty and / or the faculty Student Support Advisor (non-academic). The university as a whole does not have the specific system of personal tutors seen in many UK universities although an initial mentoring system (Academics Connections) is being developed for a small group of students perceived to be at risk.

Considerable support in studying and learning skills is available for students at the University of Wollongong via the Learning Development Centre. Small group workshops are available for more generic support, for example, Study at University, Reading Strategies, Report Writing, Presenting in Class. In addition, more discipline specific workshops are also available, such as Maths for Chemistry students, Algebra for Business Students and Calculator Skills.

Connection to and support of first year students in the first semester has also been put in place via the Staying Connected project ${ }^{16,17}$. This programme of making phone contact with each first year student individually has run since 2009 , evolving from one faculty to institutional coverage. The programme utilises trained second or later year undergraduate students to make the phone contact to provide support, tips for study and refer them to specific services if required. The attempt was made to call every first year student early on in their studies when at risk students were most likely to be considering withdrawing from subjects. This was designed as a one off call to the students with a series of informal questions to stimulate conversation with answers tabulated by the callers. In 2010 when run institution wide, $66 \%$ of first year students were successfully contacted within the first semester on-campus and this rose to $75 \%$ in the 2011 study. The 'most enjoyable' aspects of university life reported by the students were relatively consistent over the three year duration of the programme: social networks, physical environment of the campus, and institutional atmosphere always coming in the top three. Students reported that the 'most challenging' aspects were: academic expectations, adapting to the less structured and less supportive nature of university life (relative to school), and time management of study, work and social life.

Over the three year project duration it is clear that Staying Connected has proven a successful first year student early engagement facilitation tool. It is practically very difficult to make a definitive link between the Staying Connected initiative and reduced first year student attrition rates given these have many contributing factors. However, it is nonetheless encouraging to note that first year student attrition has declined across the entire on-shore population in 2011, based on students who enrolled in 2010 and that first year students reported a positive perception that 'someone cared' as to how they were faring.

While there was considerable positive feedback from the students, an important finding in the 2011 report was that $33 \%$ of students were not able to name any support services. Indeed a key recommendation for 2012 Staying Connected project is to integrate a cross-institutional monitoring and tracking system to assess first year student engagement with academic and social support services. If students remain unaware of the supports available, or perceive the need to seek help too late, or cannot find someone who can point them in the right direction or have difficulty asking for help, then the support may well not be timely. Multiple general messages about different academic, learning and other support services (in subject outline, in faculty materials, in Student Online Services) are available but are clearly not received. As yet there is no institution wide academic mentoring programme at UOW, so currently there is a 'top down' support framework reliant on the student signalling need. Thus some students can and will fall through the cracks. In contrast the academic mentoring systems of UK universities, by providing a 'bottom up' student based approach, act as a pre-emptive safety net. It would be important that such a valuable system be maintained in the face of increasing student numbers. UOW has this year initiated a mentoring system akin to this called 'Academics Connections' for students across UOW perceived to be at higher risk (first in family, low socio-economic status).

\section{Other reflections}

Transition programmes and information developed and delivered by students for students are likely to be far more relevant and successful as these incorporate student experiences from their immediate past. Often students have been swamped with induction information 'death by PowerPoint' in week zero where good teaching practice is abandoned; rather the activity should be designed like any other active learning experience which will be more engaging. Students later accessing information should be able to do this at the point of need - it must be easily retrieved by the student when required e.g. online peer produced video media.

The UOW UStart programme Facebook site was little used by students to network or discuss transition experiences and issues. This result mirrors our observation within another project that few of the students involved in a specific CHEM101-102 inclusion programme chose to feedback or communicate with their peers via the blog set up for such discussion. Some students in commenting on that project had indicated the desire for a clear distinction between their own social personal life where Facebook would be used and their academic life. We wondered whether other programmes 
incorporating social media as a communication tool find similar lack of response. It is possible that students do not want to make their social connections via UOW structures, or that they do not want to commit time to commenting on the transition programme.

\section{In conclusion}

Transition programmes will necessarily incorporate both generic and discipline specific parts. Transition and FYE support is clearly best delivered via a curriculum framework, ${ }^{9,10}$ because this is the framework within which students operate. They must engage with the degree programme so transition / FYE material and activities included in units will be covered, rather than being perceived as extracurricular and thus possibly optional. Where degree programmes are offered entirely within a department or school or faculty, control over all the components of a degree programme is easily maintained, so transition / FYE or 'cocurricular' content is easily incorporated (e.g. Law or Education Faculties ${ }^{11}$ ). Where degree programmes are made of units spread across faculties, embedding transition support via a curriculum of units housed in different faculties is very difficult. UOW has very flexible degree structures, offering a variety of mixed options. Complications will naturally arise when managing aspects of such university business across multi-discipline based degrees. Finding smart ways around this will require goodwill and effort among academic and professional learning support staff. However as the university sector as a whole in Australia is undergoing regulatory framework change ${ }^{18}$, this is a time for curriculum mapping of the discipline and generic outcomes of degree programmes, this could be viewed as a context within which strengthening of first year unit curricula on the basis of the FYE curriculum design principles can be achieved.

In the UK as student numbers increase, programmes of study diversify, and chemistry becomes a more foundation science there will be a move away from delivering multiple induction programmes at departmental level to single more generic faculty of science induction with ongoing transition support into the first year. There may also develop a need for more targeted assistance dependent on a student's degree programme and/or background. Then more UK institutions will begin to experience the issues we have outlined and discussed here.

\section{References}

1. Norton, A, 2012, Mapping Australian Higher Education, Grattan Institute, Melbourne. Accessed 12 February 2012 at

$<$ www.grattan.edu.au/

publications/122 mapping higher education.pdf>

2. Gale T, Rethinking Higher Education: Implications of the Australian Government's expansion and equity agenda. Teaching and Learning Annual Symposium CRE UNISA (July 2010). Accessed 28 Oct 2010: <www.equity101.info/files/Whyalla22July_Final.pdf>

3. Hare, J. (2012) Mass education changes face of university. The Australian 19 May 2012. $<$ www.theaustralian.com.au/higher-education/masseducation-changes-face-of-university/story-e6frgcjx1226360615106>

4. Kift, S., Nelson, K. \& Clarke, J. (2010). Transition Pedagogy: A third generation approach to FYE - A case study of policy and practice for the higher education sector. The International Journal of the First Year in Higher Education, 1(1), 1-20.
5. Bradley, D., P. Noonan, H. Nugent, \& B. Scales (2008). Review of Australian Higher Education: Final Report, Canberra: Commonwealth of Australia, accessed on 15 Mar 2011 at <www.deewr.gov.au/HigherEducation/Review/Documents/ PDF/Higher\%20Education\%20Review_one\% 20document_02.pdf>

6. James, R., Krause, K., \& Jennings, C. (2010). The first year experience in Australian Universities - Findings from 1994 - 2009. Melbourne The University of Melbourne.

7. Hassanien, A and Barber A.(2008) An Evaluation of Student Induction in Higher Education. International Journal of Management Education 6(3) 35 - 43. DOI: 10.3794/ijme.63. 208

8. Tinto, V. (2009, February). Taking student retention seriously: Rethinking the first year of university. Paper presented at the FYE Curriculum Design Symposium 2009, Queensland University of Technology, Brisbane, Australia. Retrieved May 4, 2012, from $<$ www.fyecd2009.qut.edu.au/resources/ SPE_VincentTinto_5Feb09.pdf>

9. Kift, $\bar{S}$. M. (2009a). Articulating a transition pedagogy to scaffold and to enhance the first year student learning experience in Australian higher education. Final Report for ALTC Senior Fellowship Programme. ALTC Resources. Retrieved Mar 20, 2011, from $<w w w$.altc.edu.au/resource-first-year-learning-experiencekift-2009>

10. Wilson K., Success in First Year. First Year in Higher Education Conference 2009. Accessed 1 Nov 2010 $<$ www.fyhe.com.au/past_papers/papers09/ppts/ Keithia_Wilson_paper.pdf $>$

11. UOW Report on a Trial Benchmarking Project on Academic Transition Support between the University of Wollongong and the University of Tasmania, October 2009.

<www.uow.edu.au/content/groups/public/@web/@spq/ documents/doc/uow068344.pdf> accessed 1 Jun 2012.

12. UOW FYE forum links: <focusonteaching.uow.edu.au/events/index.html\#fye1>

13. Bridge. B, Corr. S, Draper S., Scully. N. .Safe Labs for Science: an interactive approach to safety training, School of Chemistry, Trinity College, ISSN 1740-9888, New Directions, issue 3, (2007).

14. O'Brien, G. and Bedford, S. B. (2012) Small group work in large chemistry classes: Workshops in First Year Chemistry. HEAcademy STEM Annual Conference 2012. $<w w w . h e a c a d e m y . a c . u k / a s s e t s / d o c u m e n t s / s t e m-$ conference/Physical_20Sciences/Glennys_OBrien.pdf>

15. Price, G.J., and Shallcross, D.E. The impact of a preuniversity maths summer school, New Directions, Issue 7, (2011).

16. Hampton, G. (2010). Staying connected report for 2010. University of Wollongong.

17. Walder, F., and Lovegrove, B. 2011. Report to UOW University Education Committee, Nov 2011. <www.uow.edu.au/content/groups/public/@web/@gov/ documents/doc/uow124204.pdf>

18. DEEWR, 2009. Transforming Australia's Higher Education System. Accessed on 15 March 2011 at $<w w w . d e e w r . g o v . a u / H i g h e r E d u c a t i o n / D o c u m e n t s /$ TransformingAusHigherED.pdf> 